\title{
BMJ Open A co-design study to develop supportive interventions to improve psychological and social adaptation among adults with new-onset type 1 diabetes in Denmark and the UK
}

\author{
Mette Due-Christensen (D) ,1,2 Lene Eide Joensen, ${ }^{1}$ Sophie Sarre, ${ }^{2}$ \\ Ewa Romanczuk, ${ }^{3}$ Julie Lindberg Wad, ${ }^{1}$ Rita Forde, ${ }^{2}$ Glenn Robert (D) ,2 \\ Ingrid Willaing, ${ }^{1}$ Angus Forbes (D) ${ }^{2}$
}

To cite: Due-Christensen M, Joensen LE, Sarre S, et al. A co-design study to develop supportive interventions to improve psychological and social adaptation among adults with new-onset type 1 diabetes in Denmark and the UK. BMJ Open 2021;11:e051430. doi:10.1136/ bmjopen-2021-051430

- Prepublication history and additional supplemental material for this paper are available online. To view these files, please visit the journal online (http://dx.doi.org/10.1136/ bmjopen-2021-051430).

Received 22 March 2021 Accepted 29 September 2021

Check for updates

(c) Author(s) (or their employer(s)) 2021. Re-use permitted under CC BY-NC. No commercial re-use. See rights and permissions. Published by BMJ.

${ }^{1}$ Health Promotion Research, Steno Diabetes Center Copenhagen, Gentofte, Denmark ${ }^{2}$ Florence Nightingale Faculty of Nursing, Midwifery \& Palliative Care, King's College London, London, UK

${ }^{3}$ Steno Diabetes Center Odense, Odense Universitetshospital, Odense, Denmark

Correspondence to Dr Mette Due-Christensen; mdue0015@regionh.dk

\section{ABSTRACT}

Objective To develop supportive interventions for adults with new-onset type 1 diabetes (T1D) to facilitate positive adaptive strategies during their transition into a life with diabetes.

Design The study used a co-design approach informed by Design Thinking to stimulate participants' reflections on their experiences of current care and generate ideas for new supportive interventions. Visual illustrations were used to depict support needs and challenges. Initial discussions of these needs and challenges were facilitated by researchers and people with diabetes in workshops. Data comprising transcribed audio recordings of the workshop discussions and materials generated during the workshops were analysed thematically.

Settings Specialised diabetes centres in Denmark and the United Kingdom.

Participants Adults with new-onset T1D ( $\mathrm{n}=24)$ and healthcare professionals (HCPs) $(n=56)$ participated in six parallel workshops followed by four joint workshops with adults $(n=29)$ and HCPs $(n=24)$ together.

Results The common solution prioritised by both adults with new-onset T1D and HCP participants was the development of an integrated model of care addressing the psychological and social elements of the diagnosis, alongside information on diabetes self-management. Participants also indicated a need to develop the organisation, provision and content of care, along with the skills HCPs need to optimally deliver that care. The codesigned interventions included three visual conversation tools that could be used flexibly in the care of adults with new-onset T1D to support physical, psychological and social adaptation to T1D.

Conclusion This co-design study has identified the care priorities for adults who develop T1D, along with some practical conversational tools that may help guide HCPs in attending to the disruptive experience of the diagnosis and support adults in adjusting into a life with diabetes.

\section{INTRODUCTION}

A diagnosis of type 1 diabetes (T1D) can occur at any age, with around $50 \%$ of cases

\section{STRENGTHS AND LIMITATIONS OF THIS STUDY}

$\Rightarrow$ The study included a diverse sample of adults with new-onset type 1 diabetes from two countries.

$\Rightarrow \mathrm{A}$ large number of healthcare professionals across multiple disciplines from two countries took part in the study.

$\Rightarrow$ The broad approach including many different perspectives increases the transferability of the results to other contexts.

$\Rightarrow$ Although we did not find any differences between perspectives across gender, a limitation of the study is the relatively small number of male participants.

$\Rightarrow$ People with diabetes have been involved in the design and conduct of the study from inception.

presenting in adulthood. ${ }^{12}$ Developing T1D as an adult can be very disruptive, as adults have already formed many aspects of their lives: employment, relationships and lifestyle habits. ${ }^{34}$ The diagnosis introduces new responsibilities for acquiring and maintaining time-consuming self-management skills, and fears about hypoglycaemia and future diabetes complications, all of which may affect self-identity and life-plans. ${ }^{5} 6$ Previous research has identified that accommodating the demands of T1D into established life routines can lead to significant psychological and social challenges for adults with new-onset T1D. ${ }^{78}$ These challenges include difficulties in coming to terms with the diagnosis of T1D; experiencing added complexity and disruption of daily life due to managing diabetes alongside other demands; and feeling stigmatised and anxious about how the diagnosis will affect social relationships and employment. ${ }^{34}$ 
During the disruptive period following diagnosis many adults feel that their psychological and emotional needs are not adequately addressed by healthcare professionals (HCPs). ${ }^{910}$ Adults with new-onset T1D perceive that the focus of their interactions with HCPs is on providing them with the technical skills needed for blood glucose management to achieve 'good' blood glucose levels. ${ }^{4}$ This focus, when pursued without attending to the psychological and social challenges following the diagnosis of T1D, can create a sense of frustration and failure in the person with diabetes when recommended blood glucose levels are not achieved. ${ }^{34}$ Furthermore, the person may consequently be less likely to engage with their selfmanagement behaviours, thereby increasing the risk of future burdensome and costly diabetes complications. ${ }^{411}$ Hence, early intervention to support adults in developing positive adaptive strategies and self-management routines in everyday life following diagnosis may reduce these problems and may improve long-term physical and mental health outcomes.

National and international guidelines ${ }^{12} 13$ highlight the importance of addressing the psychological and social needs of adults with diabetes, however, there are no specific recommendations for how to address these needs in the adult onset T1D population. While HCPs generally recognise the importance of providing psychological and social support for adults with diabetes, ${ }^{14}{ }^{15}$ studies have reported minimal inclusion of such issues in routine diabetes care due to lack of training, tools and skills to engage in conversations about psychological and social aspects. ${ }^{16-18}$ Furthermore, access to specialist psychology services is limited in most areas. Structural barriers such as consultation time constraints due to a focus on fulfilling the requirements set by clinical guidelines and an emphasis on glucose targets also limit the capacity for psychological and social support. ${ }^{9}{ }^{17}$ Previous studies have reported that HCPs tend to overload people with information on diabetes self-management, focusing on technical issues rather than providing psychological and social support due to a fear for the person's physical safety. ${ }^{49}$ Such studies have also found that this emphasis on diabetes treatment together with the risks of hypoglycaemia and long-term complications can induce a sense of anxiety in adults with new-onset T1D. ${ }^{49}$

Overall, existing evidence shows a disconnect between the needs of adults with new-onset T1D and current earlystage care, with potentially negative consequences in relation to the person's acceptance of and engagement with their diabetes; thereby, increasing the risks of future physical and psychological morbidity. To address this problem, we have undertaken a co-design study with adults with new-onset T1D and HCPs in Denmark (DK) and the United Kingdom (UK). The aims were to explore care priorities for adults with new-onset T1D and to develop supportive interventions to facilitate a more positive transition into life with diabetes-physically, emotionally and socially— that could be tested in future feasibility trials.

\section{DESIGN AND METHODS}

The study used a co-design approach informed by Design Thinking to explore and develop interventions to support adults in adapting to T1D. ${ }^{19}$ The co-design approach in the study was aligned with the early stages of the Medical Research Council framework on developing and evaluating complex interventions to explicate mechanisms for intervention and to identify potential intervention components for future testing. ${ }^{20}$ DesignThinking typically has three integrated phases centred on stakeholder engagement and participation. ${ }^{21}$ The first phase (Inspiration) relates to exploring the target groups' physical, social and emotional needs. The second phase (Ideation) includes a process for stimulating the target population to generate, develop and test ideas that might be a solution to the needs defined in the ideation phase. In the third phase (Implementation) prototypes developed in the ideation phase are tested.

This paper presents our findings from the ideation phase, the inspiration element of the process has been reported elsewhere. ${ }^{4922}$ Prototypes that resulted from the ideation phase reported here will be tested in future feasibility trials.

\section{Study settings and participants}

The study participants were recruited from four specialist diabetes clinics in DK and two in the UK, with approximately 250 and 80 new cases of adult-onset T1D annually, respectively. The rationale for this was to consider the experiences of adults in different settings to enhance the transferability of the study outputs. T1D care in DK and the UK is similar in that it is provided by multidisciplinary specialist diabetes teams, with the only major difference being the offer of group-based evidence-based structured self-management education programmes in the UK from 6 to 12 months following diagnosis, however, the uptake is low. ${ }^{23} 24$

Eligibility criteria for study participants included: adults ( $\geq 18$ years) diagnosed with T1D within the past 5 years to ensure recollection of diagnosis and HCPs with $>1$ year experience of providing care for adults with new-onset T1D. Of 82 adults with new-onset T1D invited to participate in the study, 36 accepted the invitation and 31 attended one or more workshops. Participants were recruited according to ethical approval in each country. In the UK, potential participants were purposively sampled to achieve maximum variation in terms of age and gender and invited by letter. In DK, eligible participants were approached by clinicians following out-patient appointments. All members of the multidisciplinary diabetes team in each clinic (ranging from 4 to 35 HCPs) were invited to participate via email.

\section{Patient and public involvement}

People with T1D have been involved in the design and conduct of the study. One person with T1D was a co-applicant on one of the grants. They were also part of the advisory group with four other people with T1D, a 
Table 1 Summary of study data types and collection points

\begin{tabular}{|c|c|c|c|c|}
\hline Data collection point & Objective & Participants & Activities & Data types \\
\hline \multicolumn{5}{|l|}{$\begin{array}{l}\text { Inspiration phase } \\
\text { (previous studies) }\end{array}$} \\
\hline Interviews ${ }^{422}$ & $\begin{array}{l}\text { To explore the experience of } \\
\text { diagnosis, support needs and } \\
\text { challenges. }\end{array}$ & $\begin{array}{l}\text { Adults with } \\
\text { new-onset T1D }\end{array}$ & $\begin{array}{l}\text { Longitudinal semistructured } \\
\text { individual interviews (two } \\
\text { interviews over } 6-8 \text { months) }\end{array}$ & Transcribed interviews \\
\hline Focus groups $^{9}$ & $\begin{array}{l}\text { To explore preferences and needs } \\
\text { in relation to providing support to } \\
\text { adults with new-onset T1D. Identify } \\
\text { barriers and enablers, reflections on } \\
\text { current procedures, processes and } \\
\text { care provision at diagnosis, HCPs' } \\
\text { perceptions of issues relating to } \\
\text { provision of support to adults with } \\
\text { new-onset T1D and reflections on } \\
\text { and the identification of dilemmas/ } \\
\text { challenges in current care. }\end{array}$ & HCPs & $\begin{array}{l}\text { Exercises: } \\
\text { Story dialogue (HCPs sharing } \\
\text { their experience of a particular } \\
\text { consultation) } \\
\text { Presentation of experiences } \\
\text { of adults with new-onset T1D } \\
\text { using quotes and illustrations } \\
\text { to facilitate discussion (from } \\
\text { previous studies) }\end{array}$ & $\begin{array}{l}\text { Transcriptions of } \\
\text { discussion } \\
\text { Notes from participants } \\
\text { Field notes } \\
\text { Story dialogue notes }\end{array}$ \\
\hline $\begin{array}{l}\text { Workshops for HCPs } \\
(n=6)\end{array}$ & $\begin{array}{l}\text { To validate findings from previous } \\
\text { studies. To prioritise among identified } \\
\text { challenges from previous work } \\
\text { To generate ideas and develop } \\
\text { solutions to these challenges }\end{array}$ & HCPs & $\begin{array}{l}\text { Illustrations depicting the } \\
\text { identified challenges were used } \\
\text { to encourage discussion before } \\
\text { prioritising which were most } \\
\text { important to focus on }\end{array}$ & $\begin{array}{l}\text { Transcription from } \\
\text { audio-recorded group } \\
\text { discussions } \\
\text { Preliminary ideas on sticky } \\
\text { notes and field notes }\end{array}$ \\
\hline
\end{tabular}

HCPs, healthcare professionals; T1D, type 1 diabetes.

representative from a patient organisation and two HCPs in addition to the research team. The advisory group have played a central role in making sure that the study and its outputs are patient centred.

\section{Data collection}

We first conducted nine parallel workshops (adults with new-onset T1D in groups $(\mathrm{n}=24)$ and HCP in groups $(\mathrm{n}=56))$ and then four integrated workshops (adults with new-onset T1D $(n=29)$ and HCP $(n=24)$ in a joint workshop) to stimulate the target populations to generate, develop and test ideas for new supportive interventions. Workshops were conducted from June 2018 to October 2019. Data included audiotaped discussions from all workshops which were transcribed and sticky notes and flip charts with participants' feedback (for an overview of the process, see table 1). In the UK, three adults with T1D from the study advisory board undertook training in group facilitation together with the UK research team to co-facilitate the parallel and integrated workshops. In DK, workshops were facilitated by members of the research team. The research teams consisted of experienced clinicians and researchers.

Workshops for adults with new-onset T1D were conducted either in university or diabetes clinic rooms. Workshops for HCPs took place in the participating diabetes clinics. The parallel workshops lasted 2 hours each. The integrated workshops were also conducted either in university $(n=2)$ or diabetes clinic rooms $(n=2)$, they were 3 hours long with breaks for food and refreshment.

\section{Workshop methods}

The parallel workshops were structured to enable smaller group discussions to stimulate participants to reflect on their experiences. Illustrations depicting the common 

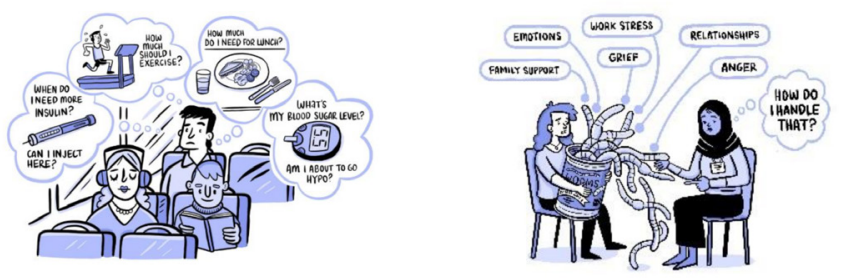

The complexity of managing diabetes

Difficulties with how to addres psychological and social issues
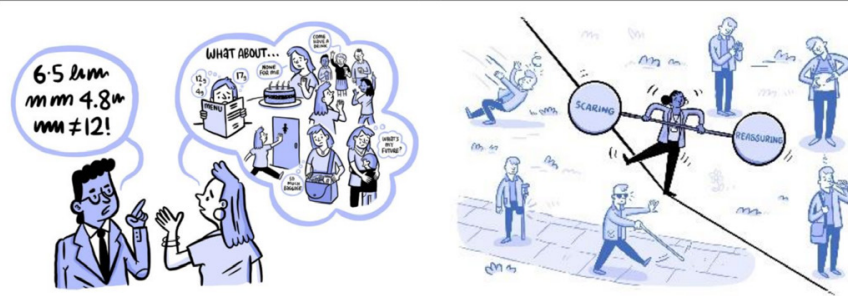

Managing diabetes alongside other demands

Balancing information

Figure 1 Examples of illustrations depicting support needs and challenges. HCP, healthcare professionals; T1D, type 1 diabetes.

support needs and challenges expressed by adults with new-onset T1D and HCPs in the inspiration phase P $22^{2}$ were used to stimulate group discussions (see figure 1 for examples). Following these facilitated discussions, participants were asked to vote on the three challenges they considered the most important to address. Brainstorming exercises in smaller groups were then used to generate as many ideas and solutions as possible related to the prioritised challenges.

In the integrated workshops, adults with new-onset T1D and HCPs voted on their top two priorities and then worked together to develop interventions to address these. Ideas and solutions from previous workshops were summarised onto cards and combined with new ideas which were gradually refined to provide prototypes of tools to support adults with new-onset T1D. Preliminary prototypes were collated and integrated by the advisory board. The prototypes were circulated via email to workshop participants for verification, comments and further suggestions for refinements. Over several iterations through emails and conversations, the prototypes were further refined into a deliverable format for testing in future feasibility trials.

\section{Data analysis}

Anonymised data from the workshops were analysed thematically for common themes among the suggested ideas and solutions for each prioritised challenge across sites and countries. The analysis followed Braun and Clarke's ${ }^{25}$ method, which is based on a five-step process:

1. Becoming familiar with the data by reading and rereading the outputs from workshops (transcriptions, post it notes, summary notes), and making notes of early impressions.

2. Generating initial codes, through looking across the dataset to compare challenges, ideas and solutions for similarities and differences within and across sites and countries.

3. Searching for common themes, by comparing the relationships between the ideas and solutions related to the prioritised challenges and organising them into broader themes.

4. Reviewing themes, by identifying patterns across the themes and labelling overarching themes for the challenges, ideas and solutions.

5. Defining and naming themes through refining the relationships between the challenges and the suggested solutions and ideas.

The initial coding of workshop data was conducted by local members of the research team and discussed with the first author (MD-C). The coding was compared for similarities and differences between sites and countries in preparation for theme development. MD-C developed preliminary themes in collaboration with SS and AF (UK) and ER and JLW (DK). These were then discussed with and refined by members of the research teams across the sites during the initial steps of the analysis process. Subsequently the whole team met to agree on the final themes and prototypes of tools.

\section{RESULTS}

Of the 31 adults with new-onset T1D participating in the study, 16 (52\%) were from DK, 20 (64\%) were women, median diabetes duration was 2.5 years (ranging from 1 to 4.5 years) and median age was 42 years (ranging from 22 to 72 years). Of the 61 HCPs participating in the study, 44 were from DK $(71 \%)$. Thirty-six were nurses $(59 \%), 14$ doctors $(23 \%), 8$ dieticians $(13 \%)$ and $3(5 \%)$ others (ie, psychologists). They had a median of 15 years (ranging from 1 to 35 years) of experience of caring for adults with new-onset T1D (see table 2). Ten HCPs (five from each country) were men, three of whom were nurses from the $\mathrm{UK}$, the remaining were doctors. Most participants were Caucasian.

Twenty-eight participants (16 adults with new-onset T1D and 12 HCPs) took part in more than one workshop.

\section{Prioritisations}

Top priorities differed slightly among the parallel workshops. The three challenges most commonly given the highest priority across the workshops for adults with newonset T1D were: (a) coming to terms with diabetes; (b) the complexity of managing diabetes in different contexts and alongside other demands and (c) fear of hypoglycaemia, high blood glucose values and complications. The HCPs workshops prioritised the following challenges as most important: (a) balancing the clinical perspective (blood glucose regulation and prevention of long-term complications) with the perspective of the adult with 
Table 2 Participants in parallel and integrated workshops

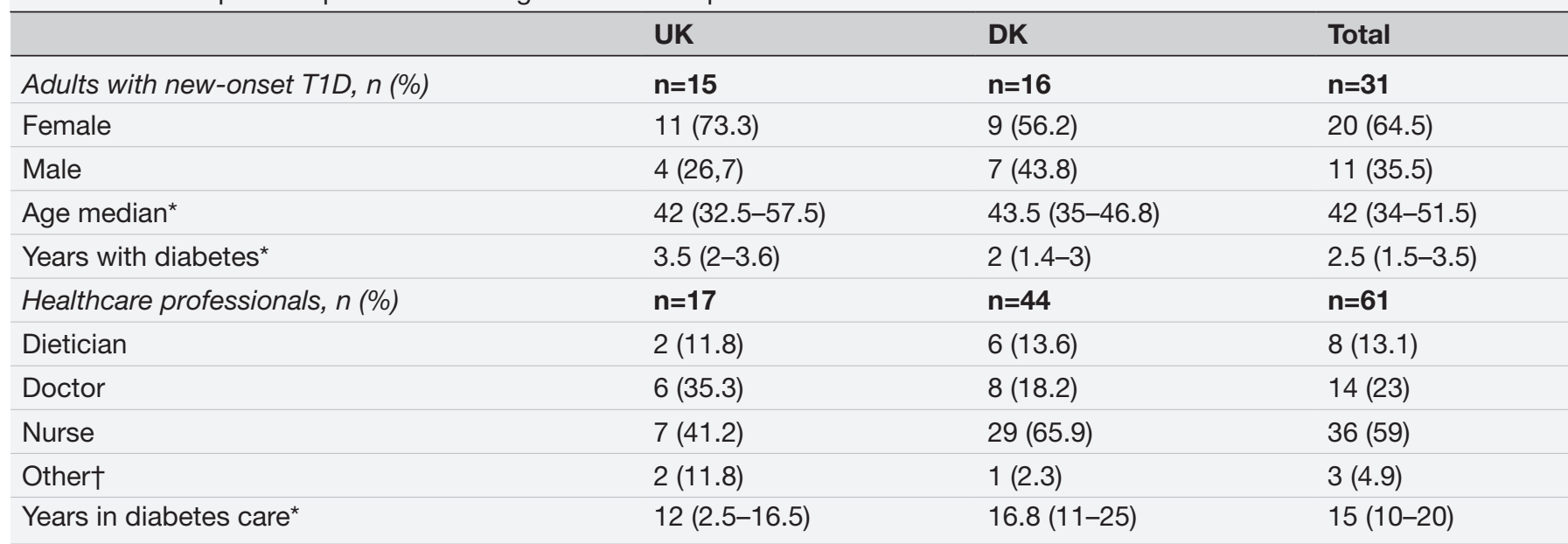

Missing data on years in diabetes care for HCPs: UK=1, DK=2.

*Median, IQR (25\%-75\%).

†Other=researcher, psychotherapist, psychologist.

DK, Denmark; HCP, healthcare professional; T1D, type 1 diabetes; UK, The United Kingdom.

new-onset T1D; (b) overloading adults with new-onset T1D with information due to fear for their physical safety and (c) difficulties with how to address psychological and social issues. The highest rated priorities from the integrated workshops were: (1) helping adults to come to terms with diabetes by addressing psychological, social and emotional issues and (2) avoiding information overload and balancing the clinical perspective with the needs of the adult with new-onset T1D to facilitate a more positive adaptation to diabetes.

\section{Solution themes}

The participants consistently suggested that diabetes care and support for adults with new-onset T1D needed to be phasic, first addressing the emotional, social and physical impact of the diagnosis, and then how to adapt to life with diabetes. Adults with new-onset T1D and HCPs both recognised the benefits of addressing psychological and social needs to enhance engagement in self-management activities and consequently reduce the risk of diabetes complications (both physical and psychological). There was a high level of agreement in the suggested solutions and ideas stated by participants (both adults with new-onset T1D and HCPs) across the two countries although the terminology used varied. Solutions to the prioritised challenges in relation to care priorities centred around four overarching themes: (1) provision of care which related to the interactions between the person with diabetes and the HCP; (2) ideal care content involved topics identified by participants as relevant and important to discuss in consultations following the diagnosis; (3) HCP care skillset, which concerned ways to support and improve HCPs skills sets and (4) organisation of care including availability and consistency of staff, timing of and mode of consultations and structure of electronic records. The themes are described in table 3 with illustrative quotes/ excerpts from workshop discussions and information on how they fed into the co-designed interventions.

\section{Prototypes of tools to support adaptation}

Through several cycles of feedback from adults with newonset T1D (via email) and HCPs (via email and feedback at multidisciplinary team meetings), the co-design process resulted in the development of three prototypes of conversation tools that could be used flexibly in the care of adults with new-onset T1D.

\section{Tool 1: the diabetes roadmap}

The aim of this tool is to express how adapting to diabetes is an on-going biomedical, psychological and social process. It lays out what the person with diabetes can expect from their diabetes care during the first year. It signposts and normalises emotional and social responses that the person with diabetes might encounter when adapting to life with T1D. The tool is visual depicting a winding road starting from the point of diagnosis. Images of different types of HCPs who adults with new-onset T1D will meet during the first year are placed on one side of the road map, and on the other side examples of thoughts and questions people might have to support them in expressing their experience of living with T1D (online supplemental file 1).

\section{Tool 2: living with diabetes}

This tool focuses on the way diabetes might affect the person's body, their thoughts and emotions and their everyday life with the aim of facilitating a dialogue on the person with T1D's own issues and emotions. It uses visual prompts with images developed from previous research, and speech bubbles signposting various ways of adapting to diabetes. The tool also involves some specific open questions to give adults with new-onset T1D 


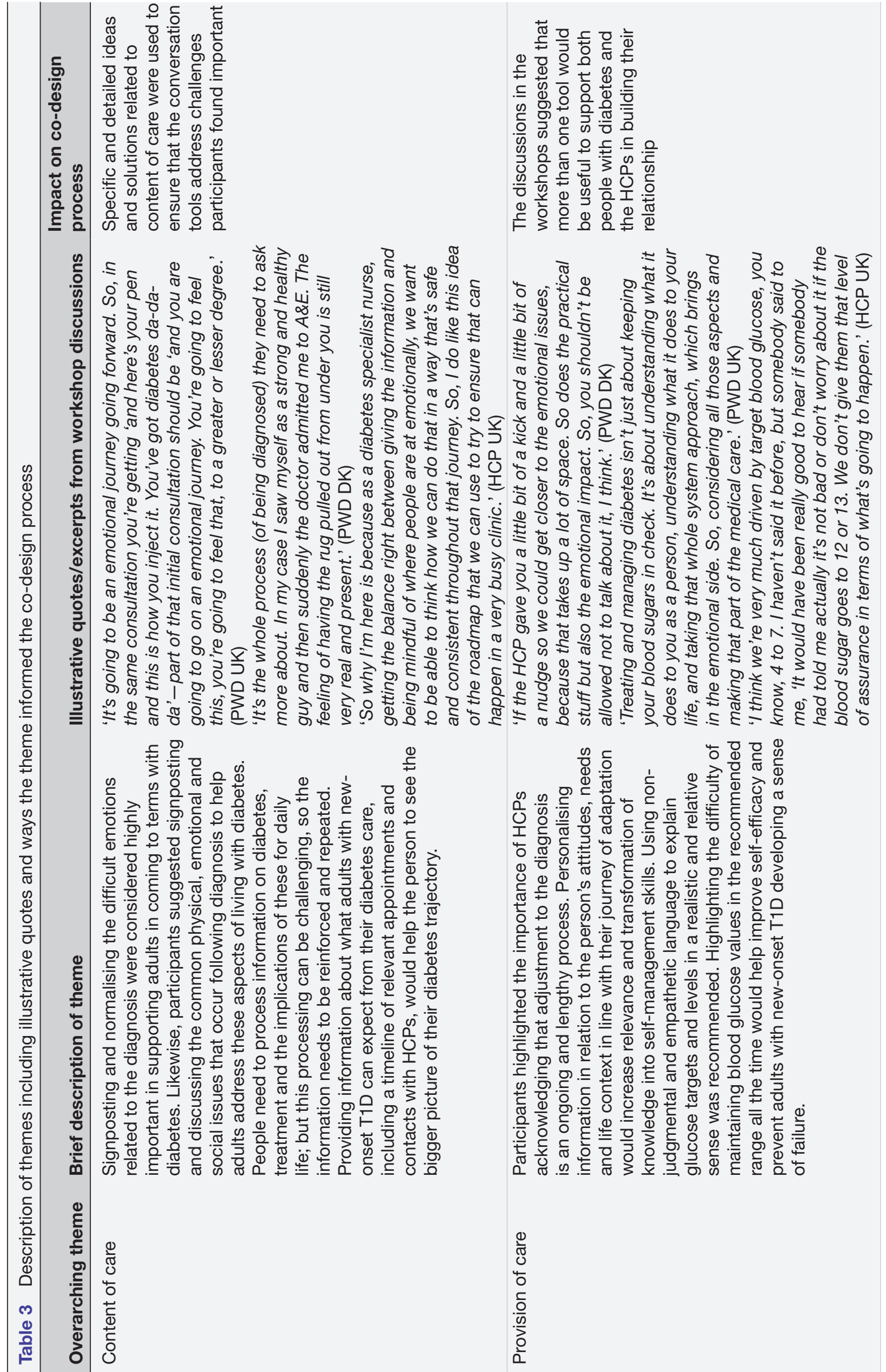

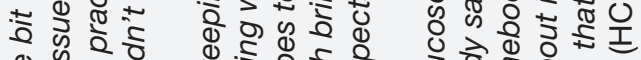
要方 ब वे की

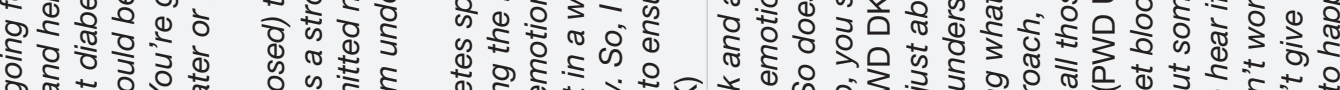
काँ

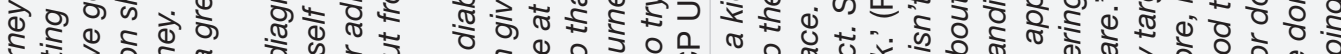

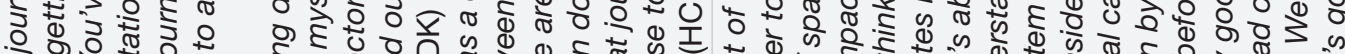
ब.

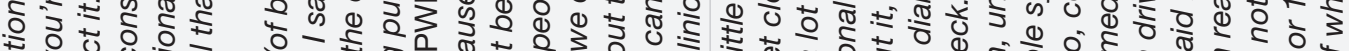
年

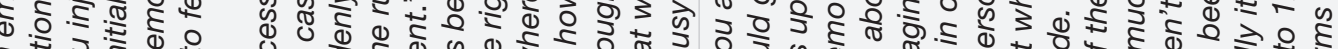

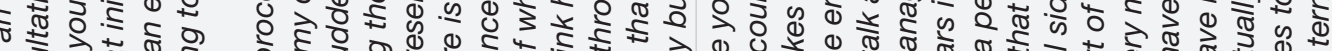
ब के

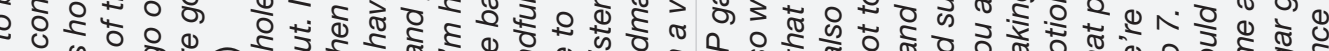
ब ब.

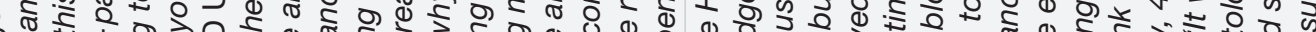

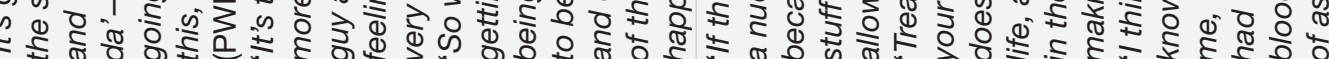

\section{弄彭}

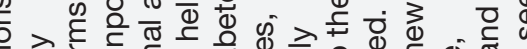

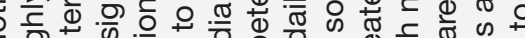

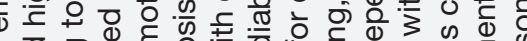

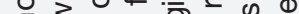
$\sum$ 두

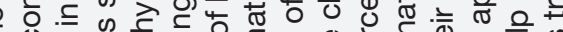

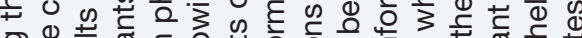

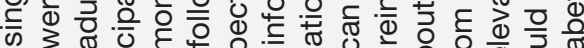
ब

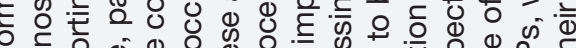

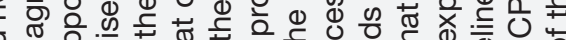
年了

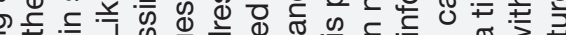
운

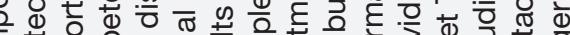

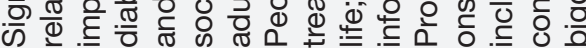

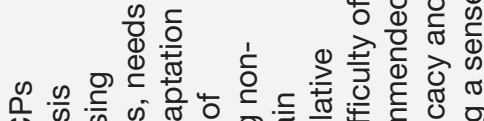

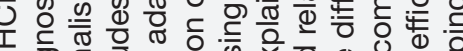
万. O 的 응 क

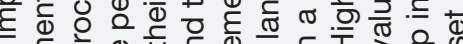

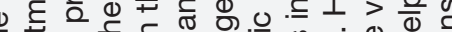

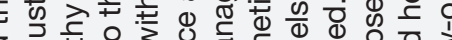
宁 항

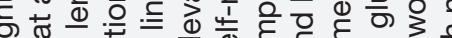
政 진

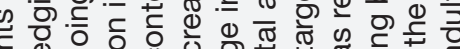

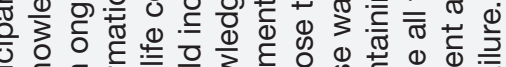

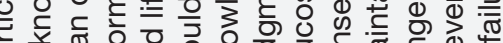

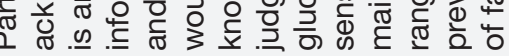




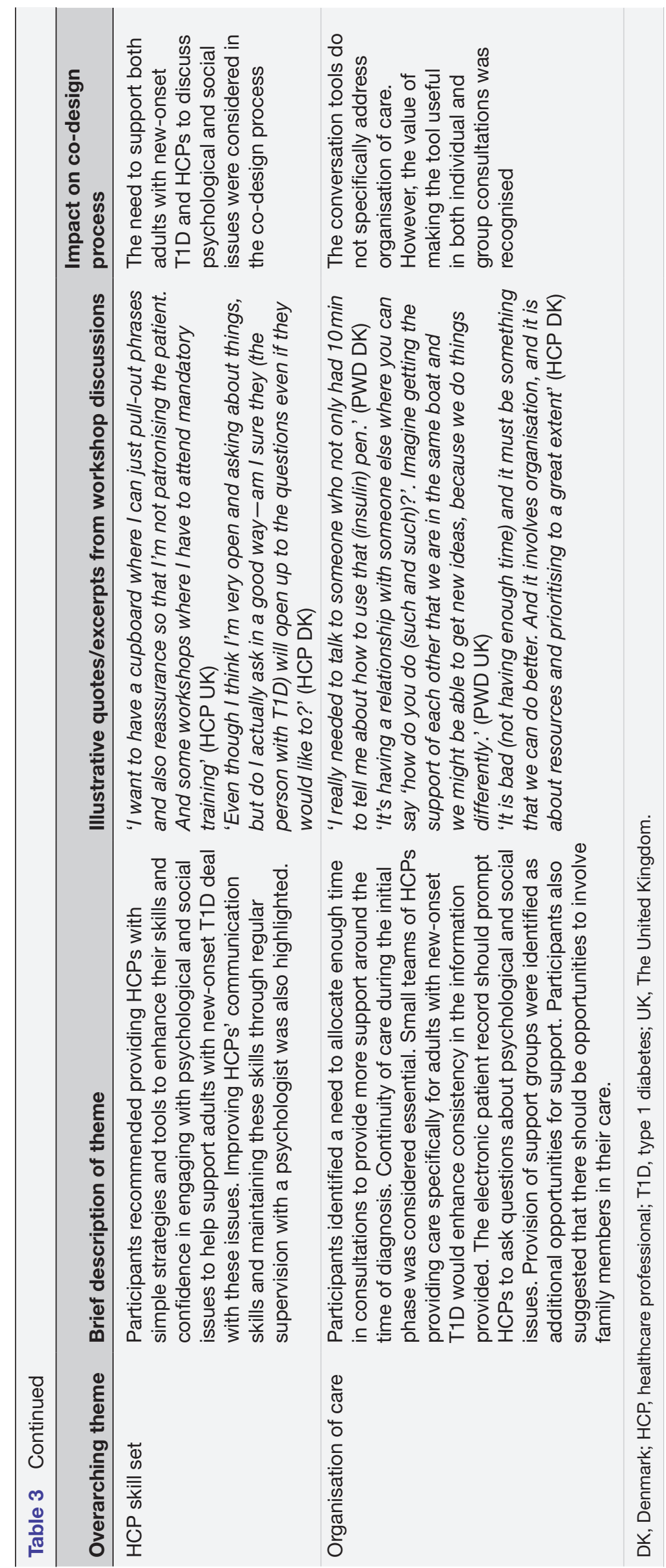


the opportunity to express and process the biomedical, psychological and social impacts of diabetes relevant to them (online supplemental file 2).

\section{Tool 3: adapting to diabetes}

Through a combination of illustrations depicting common experiences at the time of diagnosis and quotes relating to such experiences developed in an earlier study, ${ }^{22}$ this tool aims to serve as a conversation starter. Adults with new-onset T1D are encouraged to reflect on their experiences of living with diabetes, explore their own values and support them in making decisions related to self-management based on these (online supplemental file 3).

Participants suggested these tools could be used independently or in combination in both one-to-one consultations and group sessions. The advantage of one-to-one sessions was the ability to personalise the tools to reflect the life situation and specific issues of the individual. In group sessions, the tools would provide space for reflection on common challenges, sharing of experiences and normalising the adaptive process. A training manual to guide HCPs in facilitating the conversation tools will be developed to increase their skills prior to future feasibility trials.

\section{DISCUSSION}

This co-design study included a diverse sample of adults with new-onset T1D and a broad range of HCPs from DK and the UK. Participants identified support related to coming to terms with diabetes and integrating clinical demands of treatment with the individual's life situation as their top priorities for developing interventions to support early adaptation. The study showed that organisation, provision of and content of care along with HCP care skills were important features of optimal care. The study's output were three visual prototype tools to support physical, psychological and social adaptation to T1D in adults. The aims of the tools are to enable reflections on the impact of the diabetes diagnosis and establishing selfmanagement routines that will improve health outcomes long term and enhance mental, physical and social wellbeing for adults with new-onset T1D.

While optimal care is a global challenge and essential for all people with diabetes, the early phase of living with T1D provides a window of opportunity for adults to help them understand and come to terms with diabetes. This may assist them in adapting more positively to their condition from the outset in a way that will help them live well with diabetes in the future. In line with previous research, ${ }^{726} 27$ this study has highlighted the necessity of providing psychological and social support related to the disruption caused by the diagnosis and the impact this may have on identity, relationships and everyday activities for adults who develop T1D. The lack of such support in the period after diagnosis can impact and increase the risk of long-term complications, ${ }^{28}$ and might cause diabetes-related distress in the longer term. ${ }^{27} 29 \mathrm{~A}$ key concept here is that early psychological and social intervention may help ameliorate or prevent the development of longer-term maladaptive coping mechanisms (avoidance or disengagement), diabetes distress and psychological morbidities (fear and anxiety) which will increase the risks for physical complications.

The ideas and solutions suggested for improving care processes at diagnosis across the participating countries were almost identical among the adults with new-onset T1D and HCPs participants. Previous research has identified commonalities between the UK and DK in relation to the experiences and needs of adults with new-onset $\mathrm{T}^{\mathrm{D}} \mathrm{D}^{4}$ and the barriers of attending to these needs experienced by HCPs. ${ }^{9}$ The resemblance in healthcare service provision for people with T1D (free access paid through taxation, corresponding clinical roles for HCPs) might explain the similar perception and experiences of HCPs and adults with new-onset T1D across DK and the UK. Another explanation for the convergence between the two countries might be the universality of the challenges people experience following being diagnosed with a chronic condition as an adult. ${ }^{30}$ Older and recent studies involving adults with longer diabetes duration have demonstrated a common and persistent perception of challenges in life with T1D across a variety of settings. ${ }^{10}$ Such challenges include for example illness perception, ${ }^{31}{ }^{32}$ change in identity ${ }^{33}$ and acceptance of and adjustment to T1D. ${ }^{35} 36$

This study showed that need for continuity, consistency and personalisation in care delivery following diagnosis was of high importance to both the adults with T1D and HCP participants. Communication, emotional support and the quality of the relationship between the person with diabetes and their HCP have been associated with long-term impacts on diabetes self-management and quality-of-life. ${ }^{10} 37{ }^{38}$ Studies have also shown that adults with diabetes value interactions with HCPs that consider their mental well-being ${ }^{39}$ and acknowledge the complex multifaceted challenges of living with diabetes. ${ }^{40}$ In addition, the value of getting emotional support through peer support has also been highlighted in existent literature. $^{4142}$

Other studies have identified the difficulties and challenges faced by HCPs in providing emotionally therapeutic care, identifying the need to increase the awareness, skills and opportunities of HCPs for delivering such care. ${ }^{43}{ }^{44} \mathrm{~A}$ key challenge to overcome is the need to balance clinical priorities (introducing diabetes technologies safely and setting glucose levels) with the wider needs of the person with diabetes following the disruption of the diagnosis. Integrating these different agendas in consultations might improve the consultation experiences for both adults with T1D and HCPs. ${ }^{45}$ Recently, the use of diabetesrelated patient-reported outcome measures (PROMs) has been suggested as a way to incorporate psychological and social issues into consultations. ${ }^{46}$ To our knowledge, a diabetes-related PROM focusing on the psychological 
and social impact of a diagnosis of T1D has not yet been developed. Due to their limited experience with living with T1D, a reliance solely on PROMs would be limited in terms of meaningfully informing future practice and care. Alongside the refinement of better measures, developing tools specifically aimed at improving people's experiences following diagnosis by raising openness and awareness about potential challenges may help integrate adults' experiential knowledge with that of HCPs to the benefit of both parties. ${ }^{10} 4748$

The conversation tools developed in this study will not in isolation change practice. Tools need to be underpinned by common values and understanding in terms of what is necessary for their use and who can provide the support including change of practice and collaboration and what training is needed. ${ }^{40}$ Multidisciplinary teamwork with input from adults with new-onset T1D and time for discussions on approaches to care for adults with new-onset T1D are likely to increase common values and engagement with and use of the tools in clinical practise. A common approach to the tools may enhance the therapeutic interactions between HCPs and adults following diagnosis allowing for a more open dialogue in relation to how people navigate the physical, psychological and social impact of developing T1D in adulthood.

While the challenges identified and prioritised in our study are in line with previous research in adults with diabetes, this study is the first to explore and compare specific solutions to these challenges among a transnational group of both adults with new-onset T1D and HCPs. Our study highlights that challenges occur from the time of diagnosis and support is needed to address these challenges as early as possible to potentially prevent long-term psychological consequences such as high levels of diabetes distress. ${ }^{29} 51$

\section{Study limitations}

While participants identified several support needs and optimal care features in relation to adult onset T1D, the outcome of the co-design process did not attend to all challenges identified in the study. In part, this was a result of the prioritisation exercises in which the focus for the development work was agreed by consensus. The result of this process was that some areas such as care organisation were not considered to the same extent as care content areas. The conversation tools, for example, mainly address the content and provision of care during consultations. However, while care organisation was not directly addressed by the conversation tools, the study did emphasise a wider focus on psychological and social challenges as part of care delivery and this was expressed in the roadmap which set a framework for care organisation. In addition, the identification of training for HCPs and enhanced continuity are systemic interventions.

There were some differences in study design between sites. Due to different ethical approval requirements, participants were recruited differently in DK and the UK. The content of some HCP workshops was adapted due to time restrictions in terms of their availability. Involvement of people with diabetes as co-facilitators in the workshops was only possible in the UK part of the study. Another area of national divergence was in relation to some aspects of care delivery. While the healthcare systems in the UK and DK are similar, the UK offers structured evidence-based group education which is not provided in DK. However, despite these small differences, our study captured the views of a large sample of both adults with new-onset T1D and HCPs from the multidisciplinary teams across several sites in both the UK and DK.

It is important to acknowledge that we did not have any inclusion criteria or collect data relating to the ethnicity of participants. Previous research has highlighted the lack of representation from people with non-White ethnicity in T1D research. ${ }^{52}$ This omission may have meant our sample lacked representation of people with Black or Asian ethnicity. In part this reflects the fact that T1D is more prevalent in Caucasians ${ }^{53}$ and the relative homogeneity of the Danish population. Therefore, we acknowledge that while the study did include perspectives of a wide range of participants across multiple settings in two countries, the perspectives of other ethnic populations or cultural settings were not addressed in the study. Future studies should address this deficit as the experiences and perspectives of people from other ethnicities may be socially and culturally nuanced.

There was a potential gender bias in the study, with more female participants in both the people with T1D and HCPs. In terms of adults with T1D more women than men participated in the study. Previous studies of people with established T1D indicate that women and men may have different experiences of diabetes and perceptions of how diabetes impacts on their lives. ${ }^{54}{ }^{55}$ However, it is not established how divergent gender based experiences are at the point of diagnosis, indeed in our previous research which included both men and women in relation to their experiences of a T1D diagnosis found that areas of impact were common. ${ }^{4}$ While we did not systematically map perspectives according to gender in adults with T1D, our sample included both gender perspectives and the proposed solutions were consensus based, following the co-design methods outlined. Among the HCPs, nurses were the most common professional group, this partly reflects the fact that nurses formed the largest proportion of HCPs in the multidisciplinary teams of the participating centres. In the Danish centre, a further factor was that the nurses had greater availability at the time of conducting the workshops. It may also be that the psychologically and socially based subject matter of the research has seemed more relevant to nurses, however, studies have shown that psychological and social issues are considered to be important challenges by both diabetes nurses and doctors. ${ }^{56-58}$ However, while there were more nurses who participated in the study, there was a broad consensus across disciplines in relation to the identified themes and solutions. It is also important to note that a tenant of this research model is that all perspectives are 
considered relevant, as it is the ideas that they contribute rather than the volume of contribution that informs the co-design process.

Despite these limitations, we believe that due to the high level of convergence and connectivity between the views of the people with diabetes and the HCPs, the emerging ideas from the co-design process will be recognisable in the wider population and will increase the transferability of findings. Thus, the implementation of the tools is likely to be more successful if they are found effective in enhancing a more positive transition into life with T1D in future trials.

\section{CONCLUSIONS}

This co-design study has identified the care priorities for adults who develop T1D, along with some practical conversational tools that may help guide HCPs in attending to the disruptive experience of the diagnosis and support adults in adjusting into a life with diabetes. Providing more emotionally expansive support that recognises and attends to the psychological and social impact of the diagnosis, may help adults adapt more positively to their diabetes. It will be important to undertake future studies to ascertain whether such interventions will improve psychological and social outcomes, increase selfmanagement activation and care engagement, alongside metabolic outcomes, in this understudied population.

\section{Twitter Glenn Robert @gbrgsy}

Acknowledgements The authors would like to thank the people with diabetes who gave up their time to take part in the study. We also thank the health care professionals in the participating centres who were involved in the study.

Contributors MD-C, AF, LEJ, IW and GR conceptualised the study. MD-C, AF, LEJ, SS, ER, GR, JLW and RF collected data. MD-C, AF, SS, JLW and ER analysed the data. MD-C, AF and LEJ drafted the manuscript. IW, GR and SS made important intellectual contributions to the manuscript and all authors read and approved the final manuscript. MD-C acts as the guarantor for the study.

Funding This project is funded by the National Institute for Health Research (NIHR) under its Research for Patient Benefit (RfPB) Programme (Grant Reference Number PB-PG-0317-20012). The views expressed are those of the author(s) and not necessarily those of the NIHR or the Department of Health and Social Care. The work presented in this article is also supported by Novo Nordisk Foundation. Grant numbers NNF170C0028274 and NNF180C0052083. Foundation of European Nurses in Europe (FEND) has also supported the work. Grant number N/A.

Competing interests None declared.

Patient consent for publication Not applicable.

Ethics approval Written consent was obtained from all participants. The study was approved by the Danish Data Protection Agency (VD-2018-196, I-Suite 6439) and The North West Research Ethics Committee (15/NW/0528) in the UK.

Provenance and peer review Not commissioned; externally peer reviewed.

Data availability statement Data are available upon reasonable request. Data from workshops are available upon reasonable request. Please contact the corresponding author.

Supplemental material This content has been supplied by the author(s). It has not been vetted by BMJ Publishing Group Limited (BMJ) and may not have been peer-reviewed. Any opinions or recommendations discussed are solely those of the author(s) and are not endorsed by BMJ. BMJ disclaims all liability and responsibility arising from any reliance placed on the content. Where the content includes any translated material, BMJ does not warrant the accuracy and reliability of the translations (including but not limited to local regulations, clinical guidelines, terminology, drug names and drug dosages), and is not responsible for any error and/or omissions arising from translation and adaptation or otherwise.

Open access This is an open access article distributed in accordance with the Creative Commons Attribution Non Commercial (CC BY-NC 4.0) license, which permits others to distribute, remix, adapt, build upon this work non-commercially, and license their derivative works on different terms, provided the original work is properly cited, appropriate credit is given, any changes made indicated, and the use is non-commercial. See: http://creativecommons.org/licenses/by-nc/4.0/.

\section{ORCID iDs}

Mette Due-Christensen http://orcid.org/0000-0003-2604-3730

Glenn Robert http://orcid.org/0000-0001-8781-6675

Angus Forbes http://orcid.org/0000-0003-3331-755X

\section{REFERENCES}

1 Thomas NJ, Jones SE, Weedon MN, et al. Frequency and phenotype of type 1 diabetes in the first six decades of life: a cross-sectional, genetically stratified survival analysis from UK Biobank. Lancet Diabetes Endocrinol 2018;6:122-9.

2 Thunander M, Petersson C, Jonzon K, et al. Incidence of type 1 and type 2 diabetes in adults and children in Kronoberg, Sweden. Diabetes Res Clin Pract 2008;82:247-55.

3 Due-Christensen M, Zoffmann V, Willaing I, et al. The process of adaptation following a new diagnosis of type 1 diabetes in adulthood: a Meta-Synthesis. Qual Health Res 2018;28:245-58.

4 Due-Christensen M, Willaing I, Ismail K, et al. Learning about type 1 diabetes and learning to live with it when diagnosed in adulthood: two distinct but inter-related psychological processes of adaptation a qualitative longitudinal study. Diabet Med 2019;36:742-52.

5 Grant L, Lawton J, Hopkins D, et al. Type 1 diabetes structured education: what are the core self-management behaviours? Diabet Med 2013;30:724-30.

6 Beran D. Developing a hierarchy of needs for type 1 diabetes. Diabet Med 2014;31:61-7.

7 Rane K, Wajngot A, Wändell PE, et al. Psychosocial problems in patients with newly diagnosed diabetes: number and characteristics. Diabetes Res Clin Pract 2011;93:371-8.

8 Kampling H, Petrak F, Farin E, et al. Trajectories of depression in adults with newly diagnosed type 1 diabetes: results from the German multicenter diabetes cohort study. Diabetologia 2017;60:6068.

9 Due-Christensen M, Sarre S, Joensen L. Barriers and enablers to providing psycho-social support for adults with new onset type 1 diabetes. Diabetic Medicne 2020;37:90-118.

10 Beran D, Golay A. Initial versus ongoing education: perspectives of people with type 1 diabetes in 13 countries. Patient Educ Couns 2017;100:1012-8.

11 Snow R, Sandall J, Humphrey C. Use of clinical targets in diabetes patient education: qualitative analysis of the expectations and impact of a structured self-management programme in type 1 diabetes. Diabet Med 2014;31:733-8.

12 Young-Hyman D, de Groot M, Hill-Briggs F, et al. Psychosocial care for people with diabetes: a position statement of the American diabetes association. Diabetes Care 2016;39:2126-40.

13 NICE. Type 1 diabetes in adults: diagnosis and management NICE guideline CG15, 2015. Available: https://www.nice.org.uk/guidance/ ng17

14 Holt RIG, Nicolucci A, Kovacs Burns K, et al. Correlates of psychological care strategies for people with diabetes in the second Diabetes Attitudes, Wishes and Needs (DAWN2 $\left({ }^{\mathrm{TM}}\right)$ ) study. Diabet Med 2016;33:1174-83.

15 Munro N, Holt RIG, Davies MJ, et al. DAWN2 study findings: psychosocial support and structured education need to be more widespread. Practical Diabetes 2013;30:239-40.

16 Byrne JL, Davies MJ, Willaing I, et al. Deficiencies in postgraduate training for healthcare professionals who provide diabetes education and support: results from the diabetes attitudes, wishes and needs (DAWN2) study. Diabet Med 2017;34:1074-83.

17 Joensen L, Fisher L, Skinner T, et al. Integrating psychosocial support into routine diabetes care: perspectives from participants at the self-management alliance meeting 2016. Diabet Med 2019;36:847-53.

18 Fredrix M, Byrne M, Dinneen S, et al. 'It's an important part, but I am not quite sure that it is working': educators' perspectives on the implementation of goal-setting within the 'DAFNE' diabetes structured education programme. Diabet Med 2019;36:80-7. 
19 Brown T, Wyatt J. Design thinking for social innovation. Stanford Social Innovation Review 2010.

20 Craig P, Dieppe P, Macintyre S, et al. Developing and evaluating complex interventions: the new medical Research Council guidance. BMJ 2008;337:a1655.

21 Lister C, Payne H, Hanson CL. The public health innovation model: merging private sector processes with public health strengths 2017;5.

22 Due-Christensen M. The experiences of bio-psycho-social adaptation following a diagnosis of type 1 diabetes in adulthood [PhD Thesis]. King's College London, 2017.

23 Humayun MA, Jenkins E, Knott J, et al. Intensive structured education for type 1 diabetes management using BERTIE: long-term follow-up to assess impact on glycaemic control and quality of life indices. Diabetes Res Clin Pract 2018;143:275-81.

24 Harris SM, Shah P, Mulnier H, et al. Factors influencing attendance at structured education for type 1 diabetes in South London. Diabet Med 2017:34:828-33.

25 Braun V, Clarke V. Using thematic analysis in psychology. Qual Res Psychol 2006;3:77-101.

26 Kampling H, Mittag O, Herpertz S, et al. Can trajectories of glycemic control be predicted by depression, anxiety, or diabetes-related distress in a prospective cohort of adults with newly diagnosed type 1 diabetes? Results of a five-year follow-up from the German multicenter diabetes cohort study (GMDC-Study). Diabetes Res Clin Pract 2018;141:106-17.

27 Gåfvels C, Rane K, Wajngot A, et al. Follow-Up two years after diagnosis of diabetes in patients with psychosocial problems receiving an intervention by a medical social worker. Soc Work Health Care 2014;53:584-600.

28 Hesse D, Boysen L, Ridderstråle M. Adult-Onset type 1 diabetes: predictors of glycaemic control. Endocrinol Diabetes Metab 2018;1:e00038.

29 Fisher L, Hessler D, Polonsky W, et al. Diabetes distress in adults with type 1 diabetes: prevalence, incidence and change over time. $J$ Diabetes Complications 2016;30:1123-8.

30 Akyirem S, Forbes A, Wad JL. Psychosocial interventions for adults with newly diagnosed chronic disease: A systematic review.0(0):1359105321995916.

31 Broadbent E, Donkin L, Stroh JC. Illness and treatment perceptions are associated with adherence to medications, diet, and exercise in diabetic patients. Diabetes Care 2011;34:338-40.

32 Due-Christensen M, Borrild L, Larsen K. Perception and integration of people living with type 1 diabetes - an empirical study. European Diabetes Nursing 2006;3:13-18.

33 Hartog I, Scherer-Rath M, Kruizinga R, et al. Narrative meaning making and integration: toward a better understanding of the way falling ill influences quality of life. J Health Psychol 2020;25:738-54

34 Oris L, Rassart J, Prikken S, et al. Illness identity in adolescents and emerging adults with type 1 diabetes: introducing the illness identity questionnaire. Diabetes Care 2016;39:757-63.

35 Ambrosio L, Senosiain García JM, Riverol Fernández M, et al. Living with chronic illness in adults: a concept analysis. J Clin Nurs 2015;24:2357-67.

36 Abdoli S, Ashktorab T, Ahmadi F, et al. The empowerment process in people with diabetes: an Iranian perspective. Int Nurs Rev 2008;55:447-53.

37 Fisher L, Hessler D, Polonsky W, et al. Emotion regulation contributes to the development of diabetes distress among adults with type 1 diabetes. Patient Educ Couns 2018;101:124-31.

38 Fisher L, Polonsky WH, Hessler D. Addressing diabetes distress in clinical care: a practical guide. Diabet Med 2019;36:803-12.

39 Hendrieckx C, Halliday JA, Russell-Green S, et al. Adults with diabetes distress often want to talk with their health professionals about it: findings from an audit of 4 Australian specialist diabetes clinics. Can J Diabetes 2020;44:473-80.

40 Litterbach E, Holmes-Truscott E, Pouwer F, et al. 'I wish my health professionals understood that it's not just all about your $\mathrm{HbA}$ !'. Qualitative responses from the second Diabetes MILES - Australia (MILES-2) study. Diabet Med 2020;37:971-81.

41 Dale JR, Williams SM, Bowyer V. What is the effect of peer support on diabetes outcomes in adults? A systematic review. Diabet Med 2012;29:1361-77.

42 Due-Christensen M, Zoffmann V, Hommel E, et al. Can sharing experiences in groups reduce the burden of living with diabetes, regardless of glycaemic control? Diabet Med 2012;29:251-6.

43 Craven M, Simons Z, de Groot M. Diabetes distress among healthcare providers: a qualitative study. Diabetes Res Clin Pract 2019:150:211-8.

44 Entwistle VA, Cribb A, Owens J. Why health and social care support for people with long-term conditions should be oriented towards enabling them to live well. Health Care Anal 2016:1-18.

45 Röttele N, Schöpf-Lazzarino AC, Becker S, et al. Agreement of physician and patient ratings of communication in medical encounters: a systematic review and meta-analysis of interrater agreement. Patient Educ Couns 2020;103:1873-82.

46 Skovlund SE, Lichtenberg TH, Hessler D, et al. Can the routine use of patient-reported outcome measures improve the delivery of PersonCentered diabetes care? A review of recent developments and a case study. Curr Diab Rep 2019;19:84.

47 Storni C. Patients' lay expertise in chronic self-care: a case study in type 1 diabetes. Health Expect 2015;18:1439-50.

48 Zoffmann V, Harder I, Kirkevold M. A person-centered communication and reflection model: sharing decision-making in chronic care. Qual Health Res 2008;18:670-85.

49 Pals RAS, Olesen K, Willaing I. What does theory-driven evaluation add to the analysis of self-reported outcomes of diabetes education? A comparative realist evaluation of a participatory patient education approach. Patient Educ Couns 2016;99:995-1001.

50 Willaing I, Vallis M. Educating the person with diabetes. textbook of diabetes. John Wiley \& Sons, Ltd, 2017: 326-40.

51 Wylie TAF, Shah C, Connor R, et al. Transforming mental well-being for people with diabetes: research recommendations from Diabetes UK 's 2019 Diabetes and Mental Well-Being Workshop. Diabet. Med. 2019;36:1532-8.

52 Spanakis EK, Golden SH. Race/ethnic difference in diabetes and diabetic complications. Curr Diab Rep 2013;13:814-23.

53 Maahs DM, West NA, Lawrence JM, et al. Epidemiology of type 1 diabetes. Endocrinol Metab Clin North Am 2010;39:481-97.

54 Castellano-Guerrero AM, Guerrero R, Ruiz-Aranda D, et al. Gender differences in quality of life in adults with long-standing type 1 diabetes mellitus. Diabetol Metab Syndr 2020;12:64.

55 Sturt J, Dennick K, Due-Christensen M, et al. The detection and management of diabetes distress in people with type 1 diabetes. Curr Diab Rep 2015;15:101.

56 Peyrot M, Rubin RR, Siminerio LM. Physician and nurse use of psychosocial strategies in diabetes care: results of the cross-national diabetes attitudes, wishes and needs (dawn) study. Diabetes Care 2006;29:1256-62.

57 Pouwer F, Beekman ATF, Lubach C, et al. Nurses' recognition and registration of depression, anxiety and diabetes-specific emotional problems in outpatients with diabetes mellitus. Patient Educ Couns 2006;60:235-40.

58 Haugstvedt A, Hernar I, Graue M, et al. Nurses' and physicians' experiences with diabetes consultations and the use of dialogue tools in the DiaPROM pilot trial: a qualitative study. Diabet Med 2021;38:e14419. 